nasopharyngeal carcinoma and myeloid leukaemia. To provide further information on the risks of cancer from formaldehyde, we extended follow-up of 14008 male chemical workers at six factories in England and Wales.

Method The cohort was identified from employment records, and exposures to formaldehyde were classified on the basis of job title. Subjects were traced through health service records, and their mortality was compared with national death rates by the person-years method. Associations of exposure with incident upper airways cancer and leukaemia were further explored in nested case-control analyses.

Results More than 2000 additional deaths had occurred since last follow-up of the cohort. Excess deaths were observed from cancers of the oesophagus (100 v 93.2 expected), stomach (182 v 141.1), rectum ( $107 \mathrm{v} 86.8)$, liver (35 v 26.9) and lung $(813 \mathrm{v}$ 645.6), but none of these tumours exhibited a clear exposureresponse relationship. In nested case-control analyses of 115 men with upper airways cancer (including one nasopharyngeal cancer), 92 with leukaemia, and 45 with myeloid leukaemia, there were no elevations of risk in the highest exposure category $(>2$ ppm for $\geq 1$ year). When the two highest exposure categories were combined, the odds ratio for myeloid leukaemia was 1.26 (95\% CI 0.39-4.08).

Conclusions Our results provide no support for a hazard of myeloid leukaemia, nasopharyngeal carcinoma or other upper airways cancer from formaldehyde, and indicate that any excess risk of these diseases, even from relatively high exposures, is at most small.

\section{JOINT ASSOCIATION OF SMOKING AND SILICA DUST WITH LUNG CANCER RISK: A POPULATION-BASED CASE-REFERENT STUDY IN HONG KONG MEN}

Ignatius Tak-sun Yu, Lap Ah (Shelly) Tse. JC School of Public Health and Primary Care, The Chinese University of Hong Kong, Hong Kong, China

\subsection{6/oemed-2014-102362.11}

Objectives To examine the joint association of smoking and silica dust exposure with lung cancer risk.

Method This is a population-based case-referent study among Hong Kong Chinese males. We consecutively recruited 1208 newly diagnosed lung cancer cases and 1069 age-matched community referents during the period 2004-2006. We obtained each participant's lifelong smoking data, occupational history, and other important information including family cancer history. Unconditional multiple logistic regression analysis was performed to estimate the odds ratio (OR) and the 95\% confidence interval $(95 \% \mathrm{CI})$. We examined the joint association and tested potential interaction under multiplicative or additive risk model.

Results A total of 132 (10.9\%) lung cancers and 536 (50.1\%) community referents were never smokers. The prevalence of silica dust exposure among ever smokers was higher than the never smokers for both the lung cancers $(13.5 \%$ vs. $7.6 \%)$ and community referents $(6.4 \%$ vs. $3.7 \%)$. A 2.4 -fold $(95 \%$ CI: 1.05-5.52) risk of lung cancer for silica dust exposure was observed in never smokers, whilst it increased sharply to 12 -fold (95\% CI: 7.59-18.95) if the dust exposed workers were also smokers. A possible additive interaction was indicated between these two exposures but power is limited (synergy index $=1.61$, 95\% CI: $0.95-2.73$ ), particularly for the adenocarcinoma (synergy index $=1.25,95 \% \mathrm{CI}: 0.52-3.01)$.
Conclusions Our findings supports the conclusion of IARC that workers exposed to silica dust increase lung cancer risk but adds new evidence on a positive additive interaction between silica and smoking. [Research Grants Council (Project CUHK4460/ 03M), Hong Kong].

\section{WORK INTENSITY, INJURY, STRESS AND PAIN AMONG COMMERCIAL JANITORS}

Noah Seixas, Bert Stover, Nancy Simcox, Carlos Dominguez. University of Washington, Seattle, WA, USA

\subsection{6/oemed-2014-102362.12}

Objectives Commercial janitors are a relatively unseen and understudied segment of the workforce. Janitors report increasing work pressures over the past few years. We conducted a cross-sectional survey among janitors to evaluate the association of changes in work intensity and other aspects of work organisation on injury, musculoskeletal pain, disability, and stress.

Method We conducted a cross-sectional survey among commercial janitors, including both union and non-union workers, and a comparison group of union security guards using peer interviewers and electronic data collection. Work intensity was measured using a 10-point scale and outcomes including injury, musculoskeletal pain, disability, and stress were assessed for the current year, and two previous years. The association between work intensity and each outcome was evaluated, controlling for group and demographics.

Results Surveys were collected among 276 union and 78 nonunion janitors, and 76 security guards, $76 \%$ of whom were immigrants. An increase in work intensity among union janitors, and strong trend of increasing injury, pain, upper extremity disability and stress associated with work intensity was observed. Union janitors report an increase in injury over the past 3 years from 6.3 to $13.5 \%$. Multi-variable models further explore the impact of demographics and work characteristics on the increase in risk.

Conclusions Anecdotal reports of increased workload among janitors are substantiated by the reported increase in work pressure over the past three years and its association with stress, pain and injury among janitors.

\section{TIME OF EXPOSURE AND RISK OF ASBESTOS RELATED LUNG CANCER}

Bengt Järvholm, Evelina Åström. Umeå University, Umeå, Sweden

10.1136/oemed-2014-102362.13

Objectives It is well known that the risk of lung cancer decrease in ex-smokers some years after exposure have stopped and some studies indicate that the risk of asbestos related lung cancer decrease some years after the exposure had stopped. We have studied how the time after stop of exposure has influenced the risk of asbestos related lung cancer.

Method The incidence of lung cancer was studied in Swedish construction workers who had participated in health controls. The exposure to asbestos was estimated through the occupational titles. Occupational groups with highest risk of malignant mesothelioma were considered to be highly exposed to asbestos and the group with the lowest risk of malignant mesothelioma was considered to have the lowest exposure to asbestos. 